\title{
Leptin Treatment in Activity-Based Anorexia
}

\author{
Jacquelien J.G. Hillebrand, Maarten P. Koeners, Corine E. de Rijke, Martien J.H. Kas, and Roger A.H. Adan
}

Background: Activity-based anorexia (ABA) is considered an animal model of anorexia nervosa (AN). In ABA, scheduled feeding together with voluntary access to a running wheel results in increased running wheel activity (RWA), hypophagia, and body weight loss. Previously it was shown that leptin treatment reduced semi-starvation-induced byperactivity in rats. The present study was performed to confirm and extend this finding, to evaluate leptin's effect on energy balance in $A B A$.

Methods: The effects of chronic leptin treatment (intracerebroventricular, $4 \mu \mathrm{g} /$ day) in ABA rats, ad libitum-fed running rats, and sedentary rats exposed to ad libitum feeding or scheduled feeding were investigated.

Results: Leptin treatment decreased RWA in ABA rats. Additionally, leptin treatment reduced food intake and increased energy expenditure by thermogenesis in ABA rats. Ad libitum-fed running/sedentary rats or food-restricted sedentary rats did not reduce activity after leptin treatment, whereas all leptin-treated rats showed bypophagia. Body temperature was slightly increased in leptin-treated food-restricted sedentary rats.

Conclusions: Although leptin treatment reduced $R W A$ in ABA rats, it also prevented bypothermia and decreased food intake. Altogether, this resulted in a stronger negative energy balance and body weight loss in leptin-treated ABA rats.

\section{Key Words: Hyperactivity, running wheel, food restriction, temper- ature, gene expression}

A norexia nervosa (AN) is a psychiatric disorder often characterized by extreme hypophagia, body weight loss, hyperactivity, and hypothermia (Casper et al 1991; Hebebrand et al 2003; Kron et al 1978). Compared with other psychiatric disorders, AN has the highest mortality rate (Sullivan 1995).

It is hypothesized that a biological drive or alterations in certain physiologic parameters trigger food restriction and hyperactivity in AN. A candidate parameter is leptin, one of the main peripheral signaling molecules regulating energy homeostasis (Elmquist et al 1998; Schwartz et al 2000; Zhang et al 1994). Although genetic studies thus far have reported no evidence for specific disturbances in the leptin gene in AN patients (Hinney et al 1998), alterations in plasma leptin levels might still interfere with the disease. Plasma leptin levels rapidly decrease after body weight loss in humans and in rodents (Ahima et al 1996; Maffei et al 1995) and can vary between extremely low and within the low normal range in AN patients (Calandra et al 2003; Hebebrand et al 1997; Mantzoros et al 1997). On the other hand, AN patients show relative hyperleptinemia during recovery, as a result of rapid body weight gain (Hebebrand et al 1997; Mantzoros et al 1997).

The activity-based anorexia (ABA) model is used to study anorectic behavior in rodents and serves as an animal model of AN (Hall and Hanford 1954; Routtenberg and Kuznesof 1967). In ABA, voluntary wheel running in combination with scheduled feeding leads to a paradoxical increase of running wheel activity (RWA) and decrease of food intake, and as a result body weight drops below $80 \%$. Not only total RWA increases during ABA, but the distribution of activity throughout the day changes as well.

From the Department of Pharmacology and Anatomy (JJGH, MPK, CEdR, MJHK, RAHA), Rudolf Magnus Institute of Neuroscience, University Medical Center Utrecht, Utrecht; and Altrecht-Rintveld Eating Disorders (JJGH), Zeist, The Netherlands.

Address reprint requests to Dr. Roger A.H. Adan, Rudolf Magnus Institute of Neuroscience, Department of Pharmacology and Anatomy, University Medical Center Utrecht, Universiteitsweg 100, 3584 CG Utrecht, The Netherlands; E-mail: r.a.h.adan@med.uu.nl.

Received December 3, 2004; revised March 2, 2005; accepted March 7, 2005.
Rats develop food-anticipatory activity, which in general takes place 3 to 4 hours before scheduled feeding.

It has been reported by Exner et al (2000) that peripheral leptin treatment $(31 \mu \mathrm{g}$ /day) reduced hyperactivity in rats exposed to the semi-starvation-induced hyperactivity model (SIH). Leptin treatment also rescued rats from further hyperactivity when SIH had already developed. Additionally, it was shown that $\mathrm{AN}$ patients reported a higher subjective rating of motor restlessness when their serum leptin levels were low. From these data, it was proposed that leptin administration in acute AN might reduce hyperactivity, thereby improving outcome of further treatment. This proposal gives rise to some further questions, because the main physiologic role of leptin is to reduce food intake. Leptin decreases food intake through stimulation of pro-opiomelanocortin (POMC)/cocaine-amphetamine-regulated transcript neurons and inhibition of neuropeptide Y (NPY)/agoutirelated protein (AgRP) neurons in the arcuate nucleus of the hypothalamus (Cowley et al 2001; Friedman and Halaas 1998; Schwartz et al 1997). Furthermore, it has been described that leptin has metabolic effects (e.g., increased energy expenditure and thermogenesis), thereby promoting weight loss independent of hypophagia (van Dijk 2001). Whereas a reduction of hyperactivity by leptin treatment would be beneficial to ABA (or SIH) rats, a decline in food intake and increased thermogenesis would be disadvantageous. The present study was performed to confirm and extend the findings of Exner et al by investigating the effects of leptin treatment on RWA, food intake, and thermogenesis in rats exposed to the ABA model.

\section{Methods and Materials}

\section{Rats}

Female outbred Wistar WU rats (Harlan, Horst, The Netherlands) weighing $160 \mathrm{~g}$ upon arrival were individually housed in a temperature- and humidity-controlled room $\left(21^{\circ} \mathrm{C} \pm 2^{\circ} \mathrm{C}\right)$ under a 12-hour dark/light cycle (Zeitgeber time [ZT]12 = lights off). The ethics committee on the use and care of animals of Utrecht University approved all described procedures. For ethical reasons, it was decided that rats were to be removed from the experiment when their body temperature was lower than $30^{\circ} \mathrm{C}$ before feeding.

\section{Drugs}

Leptin (rat, Sigma-Aldrich, Zwijndrecht, The Netherlands) (4 $\mu \mathrm{g} /$ day) was dissolved in sterile isotonic saline and was chroni- 
cally infused (continuous for 5 days, $12 \mu \mathrm{L} /$ day) into the lateral ventricle with osmotic minipumps (Alzet model 1007D, DURECT, Cupertino California). This dose of leptin was previously shown to result in physiologic effects without being aversive (Hulsey et al 1998; Pal et al 2003; Thiele et al 1997).

\section{Surgical Procedures}

One week after arrival, all rats received transmitters (TA10TAF40 Data Sciences International, St. Paul, Minnesota) in the abdominal cavity under fentanyl/fluanisone $(.1 \mathrm{~mL} / 100 \mathrm{~g} \mathrm{IM}$ Hypnorm, Janssen Pharmaceutica, Beerse, Belgium) and midazolam (.05 mL/100 g IP; Dormicum, Hoffman-LaRoche, Mijdrecht, The Netherlands) anesthesia. After surgery, rats were treated with buprenorphin $(.05 \mathrm{~mL} / 100$ g s.c.; Temgesic, Schering-Plough, Maarssen, The Netherlands) and saline (1 mL s.c.) and were allowed to recover for 2 weeks.

For intracerebroventricular (ICV) surgery, rats were anesthetized by fentanyl/fluanisone as indicated above, the head was shaved, and the skull was exposed by a midline incision. A brain infusion cannula (Alzet, Brain infusion kit 3-5 $\mathrm{mm}$ ) was placed into the lateral ventricle $1 \mathrm{~mm}$ lateral and $1 \mathrm{~mm}$ posterior from bregma and fixed in place with two small screws and dental cement. The cannula was connected by tubing (filled with vehicle or leptin) to an osmotic minipump containing vehicle or leptin. Minipumps were placed s.c. into the flank region of the rat after overnight incubation at $37^{\circ} \mathrm{C}$. After surgery, rats were treated with buprenorphin and saline as indicated above.

\section{Experimental Set-up}

The effects of leptin treatment were investigated in ABA rats, ad libitum-fed running rats, ad libitum-fed sedentary rats, and food-restricted sedentary rats. One week after arrival, all rats ( $n$ $=64)$ received transmitters. After 2 weeks of recovery $($ day -10$)$, 32 rats were placed into running wheel cages for a training period of 10 days with ad libitum food and water intake. Running wheel activity was continuously registered with a cage registration program (Department of Biomedical Engineering, University Medical Center Utrecht, The Netherlands). The remaining 32 rats stayed in macrolon type 3 cages and had ad libitum access to food and water. At the end of day -2 (= light phase, ZT11), transmitters of all rats were activated for baseline recordings of body temperature and locomotor activity (LMA). At the end of day -1 (ZT11), running and sedentary rats were divided into restricted $(2 \times n=16)$ and ad libitum-fed $(2 \times n=16)$ groups, matched for body weight (average day-1: $224.0 \pm 1.7 \mathrm{~g}$ ) and 4-day RWA (average day-4: day-1: $4284.4 \pm 155.8$ revolutions). After ICV surgery, food was removed from the cages of the restricted groups (onset day 0, ZT12). The next days (days 1-4), the restricted rats had 1-hour access to food (ZT12 to ZT13), whereas water was continuously available. Body weight (ZT11) and food intake (ZT13) were measured daily. At the end of day 4 (ZT11), rats were decapitated. Brains (from all rats) and interscapular brown adipose tissue (BAT, from ABA rats) were rapidly removed, quickly frozen in cold $\left(-35^{\circ} \mathrm{C}\right)$ isopentane, and stored at $-80^{\circ} \mathrm{C}$.

\section{In Situ Hybridization}

Cryosections (coronal, $20 \mu \mathrm{m}$ ) of the arcuate nucleus were sliced with a cryostat (Leica, Rijswijk, The Netherlands) and thaw-mounted onto ribonuclease-free Superfrost slides (Menzel, Braunschweig, Germany). The slides were stored at $-80^{\circ} \mathrm{C}$ until processing for in situ hybridization (ISH). All cryostat sections were concurrently prepared for hybridization and used in the same assay for each probe. Sections were fixed in $4 \%$ paraformaldehyde in phosphate buffered saline (PBS) for $10 \mathrm{~min}$, washed in PBS, pretreated with .25\% acetic anhydride in $.1 \mathrm{~mol} / \mathrm{L}$ triethanolamine, washed again in PBS, and dehydrated in graded ethanol followed by $100 \%$ chloroform and $100 \%$ ethanol. ${ }^{33} \mathrm{P}-$ labeled anti-sense ribonucleic acid (RNA) probes were made with a 350-base pair (bp) rat POMC complementary deoxyribonucleic acid (cDNA) fragment (Kas et al 2003), a 286-bp rat NPY cDNA fragment (Ericsson et al 1987), and a 396-bp mouse AgRP cDNA fragment (Kas et al 2003). The sections were hybridized overnight at $72^{\circ} \mathrm{C}$ with $1 \times 10^{6} \mathrm{cpm}$ probe in buffer containing $50 \%$ deionized formamide, $2 \times$ standard saline citrate (SSC), $10 \%$ dextrane sulphate, $1 \times$ Denhardt's solution, $5 \mathrm{mmol} / \mathrm{L}$ ethylenediaminetetraacetic acid, and $10 \mathrm{mmol} / \mathrm{L}$ phosphate buffer, after $5 \mathrm{~min}$ heating at $80^{\circ} \mathrm{C}$. After hybridization, the sections were washed in $5 \times \operatorname{SCC}\left(\right.$ short, $\left.72^{\circ} \mathrm{C}\right)$ and $.2 \times \operatorname{SSC}\left(2\right.$ hours, $\left.72^{\circ} \mathrm{C}\right)$ and dehydrated in graded ethanol with $3 \mathrm{~mol} / \mathrm{L}$ ammoniumacetate. Sections were exposed to x-ray films (Kodak Bio-Max MR, Kodak, Rochester, New York) for 5 days. The films were developed, and film absorbance values (including a standard curve) were semi-quantitatively analyzed with the Microcomputer Imaging Device (Imaging Research, St. Catharines, Ontario, Canada).

\section{Quantitative Polymerase Chain Reaction}

Total RNA was prepared from BAT of ABA rats with Trizol Reagent (Invitrogen Breda, The Netherlands). Ribonucleic acid was treated with deoxyribonuclease I and was reverse transcribed to cDNA with oligodT and SuperScript II reverse transcriptase (Invitrogen). The Lightcycler real time polymerase chain reaction (PCR) system (Roche Diagnostics, Mannheim, Germany) was used for amplification and quantification of uncoupling protein 1 (UCP1) cDNA. Cyclophilin and 2-actin were used as reference genes. An amount of cDNA corresponding to $40 \mathrm{ng}$ of total RNA was amplified with the Mastermix from Lightcycler-Faststart DNA Master SYBR Green I kit (Roche Diagnostics) and the appropriate primers. Optimal $\mathrm{MgCl}_{2}$ concentrations, annealing temperature, and optimal cDNA dilution (1:10) were determined, resulting in PCR efficiencies of $>1.80$ (Table 1). All samples were measured in duplicate. Expression of UCP1 was calculated as normalized ratio relative to a calibrator $\left(R_{n}\right)$. Thus, UCP1 expression was analyzed relative to reference genes, and each sample was normalized to a calibrator sample (pooled cDNA), which was run in the same experiment (Roche Diagnostics).

\section{Data Analysis}

All data are presented as mean \pm SE. Data were analyzed with SPSS 11.5 for Windows (SPSS, Chicago, Illinois) and were controlled for normality and homogeneity.

One rat (leptin ABA) was removed from the experiment before day 4 for ethical reasons and was excluded from analysis. For all measurements, baseline levels were not significantly different between vehicle-treated and leptin-treated groups. Body temperature was measured with telemetry and analyzed as average body temperature during at least $30 \mathrm{~min}$ of inactivity in the light phase (ZT0-ZT3) (basal body temperature). Locomotor activity was also measured by telemetry and includes influences of RWA. Relative body weight, food intake, RWA, basal body temperature, and LMA were analyzed by general linear model repeated-measures analysis with Huynh-Feldt correction for Mauchlys sphericity effects, followed by $t$ tests. Final body weight, cumulative (day 0-4) food intake, total LMA, ISH data, 
Table 1. Primer Sequences, Magnesium Chloride $\left(\mathrm{MgCl}_{2}\right)$ Concentration, Annealing Temperatures, Anticipated Size of the Amplified Products, and GenBank Accession Codes of the Different Genes Studied by Quantitative Polymerase Chain Reaction

\begin{tabular}{|c|c|c|c|c|c|}
\hline Gene & Primers & $\begin{array}{c}\mathrm{MgCl}_{2} \\
(\mathrm{mmol} / \mathrm{L})\end{array}$ & $\begin{array}{c}\text { Annealing } \\
\text { Temperature }\left({ }^{\circ} \mathrm{C}\right)\end{array}$ & $\begin{array}{l}\text { Product } \\
\text { Size (bp) }\end{array}$ & GenBank \\
\hline UCP1 & $\begin{array}{l}\text { Forward CCACATAGGCGACTTGGA } \\
\text { Reverse TTCGTGGTCTCCCAGCATAG }\end{array}$ & 4 & 63 & 79 & NM_012682 \\
\hline Cyclophilin & $\begin{array}{l}\text { Forward ATGTGGTCTITGGGAAGGTG } \\
\text { Reverse GAAGGAATGGTTTGATGGGT }\end{array}$ & 4 & 59 & 161 & NM_022536 \\
\hline$\beta$-actin & $\begin{array}{l}\text { Forward CGTTGACATCCGTAAAGACC } \\
\text { Reverse TAGAGCCACCAATCCACACA }\end{array}$ & 4 & 59 & 177 & NM_031144 \\
\hline
\end{tabular}

and quantitative PCR data were analyzed by independent $t$ tests. Differences were considered significant at $p<.05$.

\section{Results}

\section{Effects of Leptin Treatment on Activity}

Leptin treatment ( $4 \mu \mathrm{g} /$ day) significantly decreased RWA over time in ABA rats [day: $F(4,52)=20.38, p<.001$; day $\times$ treatment: $F(4,52)=15.37, p<.001]$. Running wheel activity was reduced during the dark phase [day: $F(4,52)=15.24, p<.001$; day $\times$ treatment: $F(4,52)=10.88, p<.001$ ] as well as during the light phase [day: $F(4,52)=11.21, p<.001$; day $\times$ treatment: $F(4,52)$ $=9.87 p<.001]$. Whereas vehicle-treated ABA rats developed hyperactivity and food-anticipatory activity in the hours before feeding, leptin-treated ABA rats showed low levels of RWA.

In contrast, leptin treatment $(4 \mu \mathrm{g} / \mathrm{day})$ did not significantly affect RWA over time in ad libitum-fed rats [day: $F(4,56)=6.66$, $p=.01$; day $\times$ treatment: $F(4,56)=.03$, ns]. Neither running during the dark phase nor running during the light phase was affected in ad libitum-fed rats [dark day: $F(4,56)=6.89, p=.01$; day $\times$ treatment: $F(4,56)=.02$, ns; light day: $F(4,56)=3.82, p=$ .03 ; day $\times$ treatment: $F(4,56)=.76$, ns) (Figure 1$)$.

Locomotor activity measurements by telemetry allowed locomotion assessment in running rats and sedentary rats. Total LMA was significantly decreased by leptin treatment in ABA rats [ $t(9)$ $=2.14, p=.03]$ but not in food-restricted sedentary rats $[t(12)=$ -.75 , ns]. Similar to that seen in the RWA data, leptin treatment did not affect total LMA in ad libitum-fed running rats $[t(14)=$ $.40, \mathrm{~ns}]$ nor in ad libitum-fed sedentary rats $[t(14)=-1.08, \mathrm{~ns}]$ (Table 2).

\section{Effects of Leptin Treatment on Food Intake and Body Weight}

Leptin treatment decreased cumulative food intake in ABA rats $[t(13)=9.37, p<.001]$ and tended to decrease body weight $[t(13)=1.87, \mathrm{~ns}]$. Ad libitum-fed running and ad libitum-fed sedentary rats decreased food intake $[t(14)=4.27, p<.001$ and $t(14)=7.48, p<.001$, respectively $]$ and body weight $[t(14)=$
A
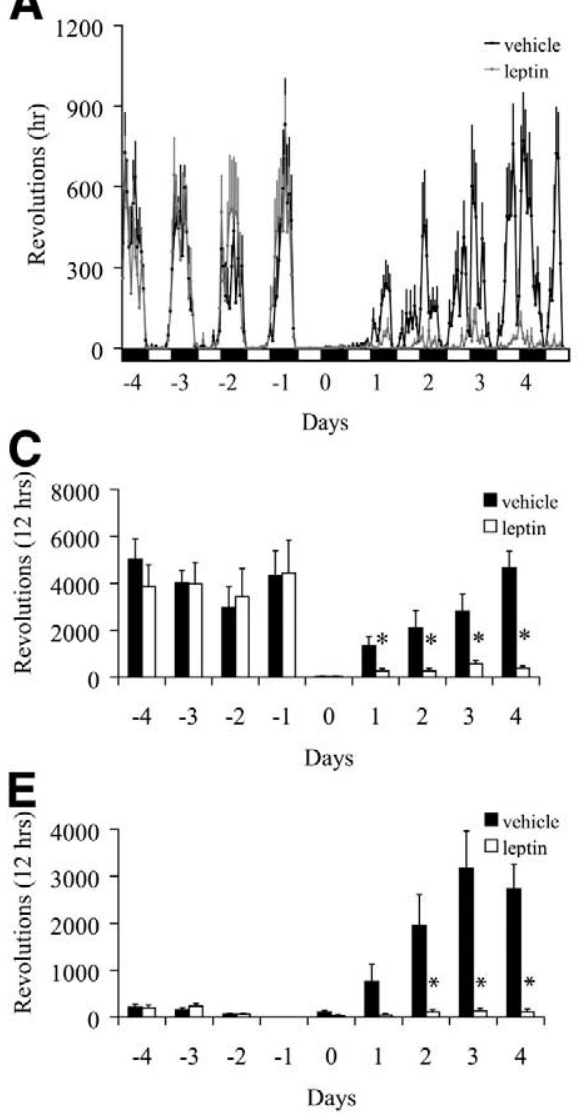

B

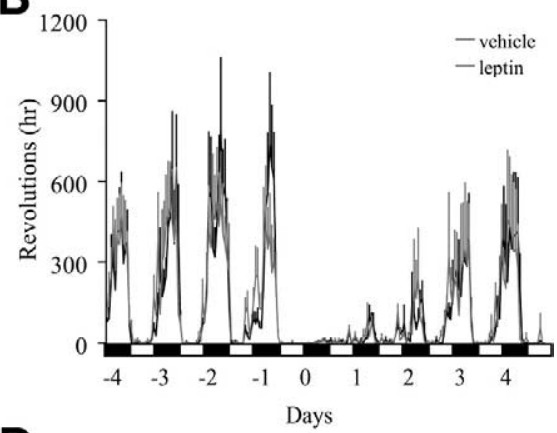

D
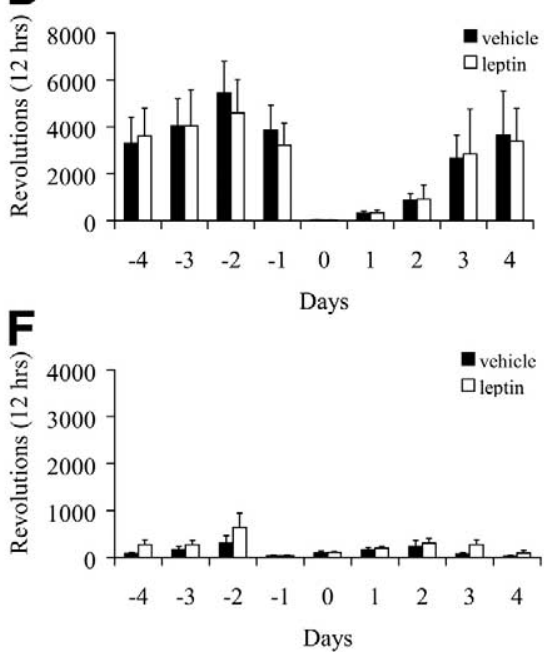

Figure 1. Running wheel activity (RWA) in rats after vehicle or leptin (4 $\mu \mathrm{g} /$ day) treatment (A, B) Distribution of RWA during the day in (A) activity-based anorexia (ABA) rats and (B) ad libitum-fed rats with vehicle (black, $n=8 / n=8$ ) or leptin treatment (gray, $n=7 / n=8)$. Leptin infusion started at day 0 . (C, D) Total dark phase RWA per day in (C) ABA rats and (D) ad libitum-fed rats with vehicle (black, $n=8 / n=8$ ) or leptin treatment (white, $n=7 / n=8)$. ( $E, F)$ Total light phase RWA per day in (E) ABA rats and (F) ad libitum-fed rats with vehicle (black, $n=8 / n=8$ ) or leptin treatment (white, $n=7 / n=8$ ). *Different from vehicle. Repeated measurements followed by $t$ tests, $p<.05$. 
Table 2. Cumulative Food Intake, Relative Body Weight, and Total Locomotor Activity (LMA) After 5 Days of Leptin (4 $\mu$ g/Day) or Vehicle Treatment in Activity-Based Anorexia (ABA) Rats, Ad Libitum-Fed Running Rats, Food-Restricted Sedentary Rats, and Ad Libitum-Fed Sedentary Rats

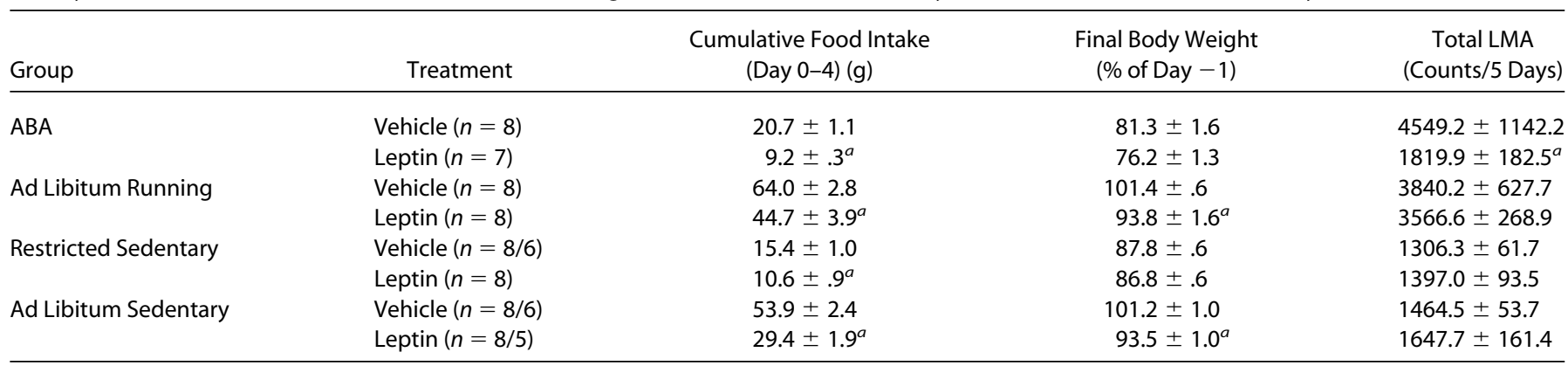

In some groups, LMA was not obtained from each rat.

${ }^{a}$ Different from vehicle treatment. $T$ test, $p<.05$.

4.32, $p<.001$ and $t(14)=5.52, p<.001$, respectively] after leptin treatment, whereas leptin-treated food-restricted sedentary rats showed a decreased cumulative food intake $[t(14)=2.40, p$ $=.03]$ with unchanged body weight $[t(14)=1.23$, ns $]$ (Table 2$)$

\section{Effects of Leptin Treatment on Thermogenesis}

Body temperature was analyzed during periods of physical inactivity in the light phase. As a result of negative energy balance, body temperature dropped in ABA rats and foodrestricted sedentary rats. Leptin treatment significantly affected body temperature over time in ABA rats [day $F(4,40)=31.5, p<$ .001 ; day $\times$ treatment: $F(4,40)=13.65, p=.01]$. Starvationinduced hypothermia was prevented by leptin treatment during days $0-3$ (all $p<.03$ ); however, on day 4 body temperature of leptin-treated ABA rats suddenly (within 1 day) dropped as compared with vehicle-treated ABA rats $(p=.03)$. In foodrestricted sedentary rats, body temperature was also influenced by leptin treatment over time [day: $F(4,48)=49.48, p<.001$; day $\times$ treatment: $F(44,48)=12.52, p<.001]$. Leptin treatment prevented hypothermia on days $2-4$ (all $p<.01$ ) in foodrestricted sedentary rats. In contrast, leptin treatment did not influence body temperature over time in ad libitum-fed running [day $F(4,56)=19.50, p<.001$; day $\times$ treatment: $F(4,56)=1.62$, ns] or in ad libitum-fed sedentary rats [day: $F(4,56)=17.98, p<$ .001 ; day $\times$ treatment: $F(4,56)=.83$, ns] (Figure 2$)$.

Because leptin-treated ABA rats showed a sudden drop of body temperature on day 4, the experiment was terminated. Severe exhaustion of the leptin-treated rats was visible by absence of visceral fat pads and extreme reddish BAT. Therefore, the expression of UCP1 in BAT was analyzed by quantitative PCR. UCP1 expression was 2.4-fold increased in leptin-treated ABA rats $\left(\mathrm{R}_{\mathrm{n}}=4.0 \pm .6\right)$ as compared with vehicle-treated ABA rats $\left(\mathrm{R}_{\mathrm{n}}=1.7 \pm .5\right)[t(6)=-2.89, p=.03]$.

\section{Effects of Leptin Treatment on Arcuate Nucleus Gene Expression}

In situ hybridization on brain slices showed that leptin treatment increased POMC messenger RNA (mRNA) levels $[t(11)$ $=-3.51, p=.01]$ and reduced AgRP $[t(11)=2.99, p=.03]$ and NPY mRNA levels $[t(11)=2.68, p=.04]$ in ABA rats. Foodrestricted sedentary rats treated with leptin also had increased POMC mRNA levels [ $t(9)=-2.61, p=.03]$ and decreased AgRP mRNA levels $[t(9)=2.25, p=.05]$, but NPY mRNA levels were not significantly affected $[t(9)=1.22$, ns]. Leptin treatment in ad libitum-fed running and ad libitum-fed sedentary rats only
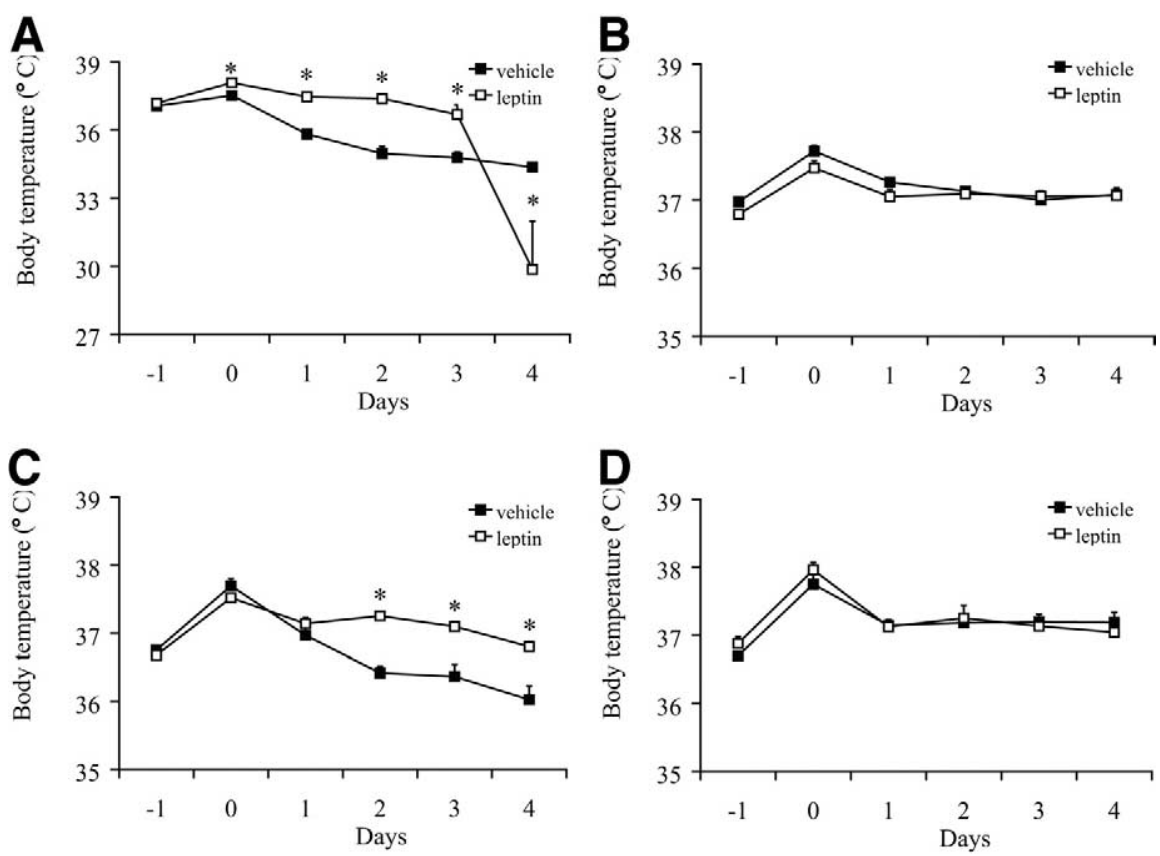

Figure 2. Body temperature in rats after vehicle or leptin $(4 \mu \mathrm{g} /$ day) treatment. Body temperature was measured during 30 min of inactivity in the early light phase. (A) Body temperature per day in activity-based anorexia (ABA) rats after vehicle (black, $n=7$ ) or leptin (white, $n=5$ ) treatment. (B) Body temperature per day in ad libitum-fed running rats after vehicle (black, $n=8$ ) or leptin (white, $n=8$ ) treatment. (C) Body temperature per day in food-restricted rats after vehicle (black, $n=6$ ) or leptin (white, $n=8$ ) treatment. (D) Body temperature per day in ad libitum-fed sedentary rats after vehicle (black, $n=8$ ) or leptin (white, $n$ $=8$ ) treatment. *Different from vehicle. Repeated measurements followed by $t$ tests, $p<.05$. Note a different $\mathbf{y}$-axis in $\mathbf{A}$. 

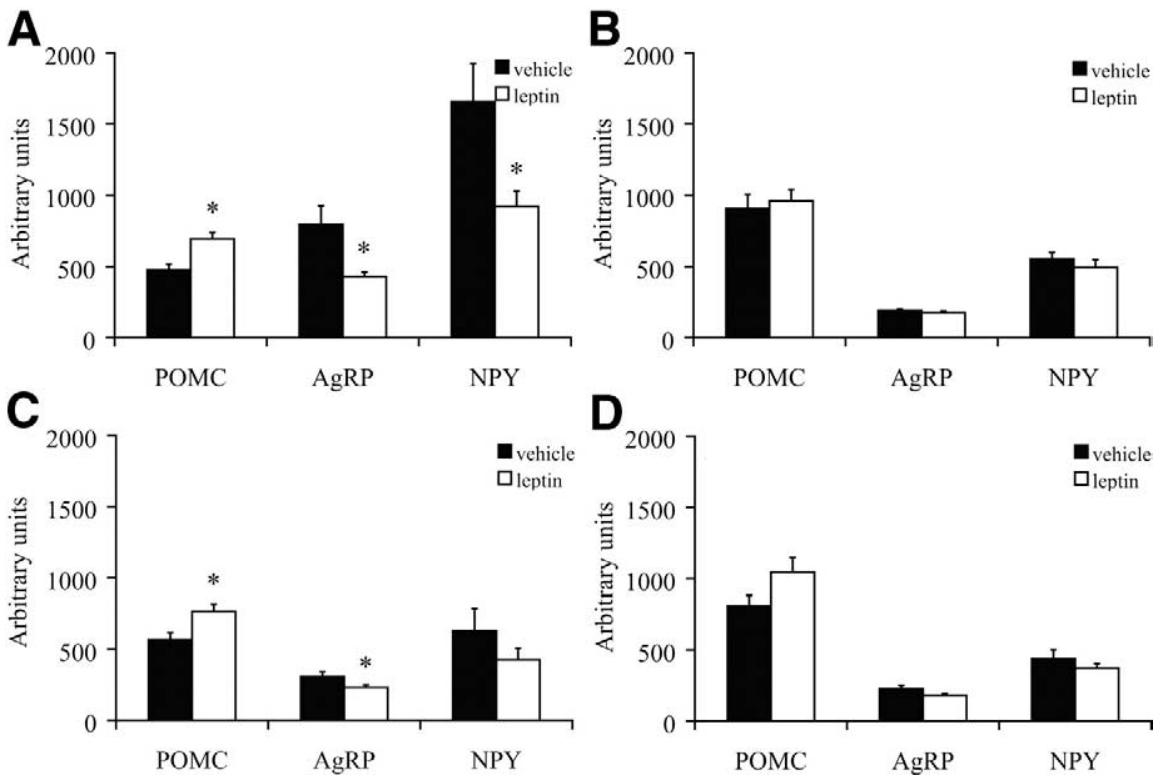

Figure 3. Pro-opiomelanocortin (POMC), agouti-related protein (AgRP), and neuropeptide $\mathrm{Y}$ (NPY) gene expression in rats treated with vehicle or leptin (4 $\mu \mathrm{g} /$ day). (A) Arcuate nucleus gene expression of POMC, AgRP, and NPY in ABA rats after vehicle (black, $n=6$ ) or leptin (white, $n=7$ ) treatment. (B) Arcuate nucleus gene expression of POMC, AgRP, and NPY in ad libitum-fed running rats after vehicle (black, $n=7$ ) or leptin (white, $n=7$ ) treatment. (C) Arcuate nucleus gene expression of POMC, AgRP, and NPY in food-restricted rats after vehicle (black, $n$ $=5$ ) or leptin (white, $n=6$ ) treatment. (D) Arcuate nucleus gene expression of POMC, AgRP, and NPY in ad libitum-fed sedentary rats after vehicle (black, $n$ $=7$ ) or leptin (white, $n=8$ ) treatment. *Different from vehicle. $T$ test, $p<.05$. resulted in trends towards upregulation of POMC and downregulation of AgRP and NPY gene expression (Figure 3).

\section{Discussion}

Leptin treatment suppressed RWA in the ABA model. This effect was specific for ABA rats, because RWA and LMA were not decreased in ad libitum-fed (running and sedentary) rats after leptin treatment. Additionally, leptin treatment did not affect LMA in food-restricted sedentary rats.

The effect of leptin treatment $(4 \mu \mathrm{g} / \mathrm{day} \mathrm{ICV})$ on RWA in ABA rats seems to be solid and strong and confirms the suppression of RWA in SIH as reported before (Exner et al 2000). The unchanged activity levels in leptin-treated ad libitum-fed rats also corresponds with earlier reports (Fox and Olster 2000; Surwit et al 2000). Food-restricted sedentary rats did not reduce activity when treated with leptin. Thus, reduced activity after leptin treatment was specific for ABA. The mechanism underlying the activity-reducing effects of leptin treatment in ABA rats is not clear. Previously it was shown that leptin reverses food-restriction-induced sensitization to brain stimulation reward (Carr 1996; Fulton et al 2000). Leptin also attenuates heroin seeking after food restriction (Shalev et al 2001). This suggests that leptin plays a role in behavioral allocation, which in the ABA model would mean that leptin might decrease the rewarding value of wheel running in ABA. The presence of leptin receptors in the midbrain dopamine system (a system involved in motivational behavior) and reduced activity of midbrain dopamine neurons after leptin treatment support this view (Figlewicz et al 2003; Krugel et al 2003).

The effect of leptin treatment on RWA in ABA rats was more pronounced than described before in SIH (Exner et al 2000). This might be explained by differences in the feeding schedules that were used (60\% of baseline food intake vs. 1-hour feeding) and dose and route of leptin administration (peripherally $31 \mu \mathrm{g} /$ day vs. ICV $4 \mu \mathrm{g} /$ day). Furthermore, we used female rats, which are relatively more sensitive to leptin treatment than male rats (Clegg et al 2003).

Leptin treatment decreased food intake in ad libitum-fed (running and sedentary) rats but also in food-restricted sedentary rats and even more in $\mathrm{ABA}$ rats, indicating that leptin has large effects on feeding behavior even during a strong homeostatic drive to eat (Ahima et al 1996; Velkoska et al 2003). Despite the negative energy balance due to ABA, leptin still increased POMC and decreased AgRP and NPY mRNA expression in the arcuate nucleus. Similar results for POMC and AgRP mRNA expression were obtained in food-restricted sedentary rats; however, NPY expression was not significantly changed.

Leptin treatment prevented the starvation-induced decrease of body temperature during the first days of ABA. Thus, on one hand leptin-treated ABA rats showed reduced energy output due to relative hypoactivity, whereas on the other hand they showed increased energy output by generating heat. The experiment showed that the effects of the reduced energy expenditure through relative hypoactivity were outweighed by the reduced energy intake and the relative hyperthermia. On day 4 , severe hypothermia was observed in leptin-treated ABA rats, and therefore the experiment was terminated. Whereas leptin treatment did not influence body temperature in ad libitum"fed rats (running and sedentary), it did prevent the starvation-induced decrease of body temperature in food-restricted rats without running wheels. Thermogenic effects of leptin have been described before (van Dijk 2001). Leptin deficient $\mathrm{ob} / \mathrm{ob}$ mice show hypothermia and have difficulties regulating body temperature in a cold environment. Leptin treatment of ob/ob mice increases body temperature (Harris et al 1998). The thermogenic response of leptin is attributed to increased sympathetic activation of BAT thermogenesis (Collins et al 1996; Satoh et al 1998). Indeed, increased expression of UCP1 in BAT of leptin-treated ABA rats as compared with vehicle-treated ABA rats was observed.

Recently it was demonstrated that chronic ICV AgRP (83-132) treatment increased survival in ABA rats (Kas et al 2003). Regarding inhibitory actions of leptin on AgRP expression and opposite actions of leptin and AgRP on energy intake, the suppressing effects of leptin on SIH (Exner et al 2000) and the stimulatory effects of $\mathrm{AgRP}_{(83-132)}$ on survival in the ABA model (Kas et al 2003) seemed contradictory before. Here it was shown, however, that leptin treatment in ABA positively influenced energy balance by decreasing RWA, but at the same time it negatively influenced energy balance in ABA by decreasing food intake and increasing thermogenesis through increased UCP1 expression. Previously, Kas et al (2003) reported that AgRP (83-132) 
positively influenced survival by increasing food intake without affecting RWA. Treatment with $\mathrm{AgRP}_{(83-132)}$ also inhibited starvation-induced hypothermia (Kas et al 2003). It has also been reported, however, that $\mathrm{AgRP}_{(83-132)}$ treatment decreases BAT UCP1 levels (Small et al 2001), opposite to the effect of leptin (Satoh et al 1998). Thus, the beneficial effects of $\operatorname{AgRP}_{(83-132)}$ on ABA are mediated differently than by leptin, which only by decreasing RWA positively affects energy balance (and thus outcome)

The strong effects of leptin treatment on food intake, RWA, and body temperature in ABA rats suggest hypersensitivity toward leptin treatment. Reduced RWA after leptin treatment supports the notion that a decrease in serum leptin levels triggers hyperactivity in ABA rats. Also in AN, a relationship between (endogenous) serum leptin levels and activity levels has been demonstrated. Anorexia nervosa patients display the highest activity levels when their serum leptin levels are lowest, whereas their activity levels are decreased when body weight and leptin levels are increased (Exner et al 2000; Holtkamp et al 2003). Variances in hyperactivity levels among AN patients correlate with serum leptin levels but not with body mass index (BMI), suggesting that hypoleptinemia, rather than a reduced BMI, might underlie physical hyperactivity (Holtkamp et al 2003). After weight gain, AN patients show relative hyperleptinemia, which seems to be related to renewed weight loss and relapse (Hebebrand et al 1997; Holtkamp et al 2004; Mantzoros et al 1997).

In summary, we demonstrated that leptin treatment strongly decreased RWA in ABA; however, decreased RWA was outweighed by reduced food intake and increased energy output by thermogenesis. Food intake suppression and increased thermogenesis resulted in a rapid worsening of the physical state of the rats. Thus, in the present study, with prolonged scheduled feeding, chronic leptin treatment was not effective in rescuing rats from ABA.

Animal data from the present study and from Exner et al are convincing and show that hyperactivity in animals receiving scheduled feeding can be reduced by leptin treatment. One should, however, be careful in extrapolating these findings to the human situation of AN. Although endogenous leptin levels in AN patients seem to be related to their physical activity levels, no direct evidence has yet been provided that leptin therapy also reduces hyperactivity in humans. Considering the animal data, leptin might have great potential as a medication for treatment of severe hyperactivity (and potentially for severe hypothermia) in AN patients; however, if these patients do not eat, leptin treatment could potentially imply an earlier death. Initial treatment in AN patients should ensure a high food intake and body weight gain. Considering the fact that this is already difficult to achieve in medication-free AN patients, treating these patients with a strong anorexic agent, like leptin, provides a serious additional concern. We believe, however, that leptin treatment could be beneficial in extremely active AN patients by decreasing hyperactivity and making them more susceptible to further treatment. As indicated above, sufficient food intake (e.g., nasogastric) and possibly a heated environment during leptin treatment should be ensured.

We thankJ. H. Brakkee for assistance with the animal work. JJGH was supported by Netherlands Organization of Scientific Research grant 9033175, The Netherlands.

Ahima RS, Prabakaran D, Mantzoros C, Qu D, Lowell B, Maratos-Flier E, et al (1996): Role of leptin in the neuroendocrine response to fasting. Nature 382:250-252.

Calandra C, Musso F, Musso R (2003): The role of leptin in the etiopathogenesis of anorexia nervosa and bulimia. Eat Weight Disord 8:130-137.
Carr KD (1996): Feeding, drug abuse, and the sensitization of reward by metabolic need. Neurochem Res 21:1455-1467.

Casper RC, Schoeller DA, Kushner R, Hnilicka J, Gold ST (1991): Total daily energy expenditure and activity level in anorexia nervosa. Am J Clin Nutr 53:1143-1150.

Clegg DJ, Riedy CA, Smith KA, Benoit SC, Woods SC (2003): Differential sensitivity to central leptin and insulin in male and female rats. Diabetes 52:682-687.

Collins S, Kuhn CM, Petro AE, Swick AG, Chrunyk BA, Surwit RS (1996): Role of leptin in fat regulation. Nature 380:677.

Cowley MA, Smart JL, Rubinstein M, Cerdan MG, Diano S, Horvath TL, et al (2001): Leptin activates anorexigenic POMC neurons through a neural network in the arcuate nucleus. Nature 411:480-484.

Elmquist JK, Maratos-Flier E, Saper CB, Flier JS (1998): Unraveling the central nervous system pathways underlying responses to leptin. Nat NeurosCi $1: 445-450$.

Ericsson A, Schalling M, McIntyre KR, Lundberg JM, Larhammar D, Seroogy K, et al (1987): Detection of neuropeptide $Y$ and its mRNA in megakaryocytes: Enhanced levels in certain autoimmune mice. Proc Natl Acad Sci U S A 84:5585-5589.

Exner C, Hebebrand J, Remschmidt H, Wewetzer C, Ziegler A, Herpertz S, et al (2000): Leptin suppresses semi-starvation induced hyperactivity in rats: Implications for anorexia nervosa. Mol Psychiatry 5:476-481.

Figlewicz DP, Evans SB, Murphy J, Hoen M, Baskin DG (2003): Expression of receptors for insulin and leptin in the ventral tegmental area/substantia nigra (VTA/SN) of the rat. Brain Res 964:107-115.

Fox AS, Olster DH (2000): Effects of intracerebroventricular leptin administration on feeding and sexual behaviors in lean and obese female Zucker rats. Horm Behav 37:377-387.

Friedman JM, Halaas JL (1998): Leptin and the regulation of body weight in mammals. Nature 395:763-770.

Fulton S, Woodside B, Shizgal P (2000): Modulation of brain reward circuitry by leptin. Science 287:125-128.

Hall JF, Hanford PV (1954): Activity as a function of a restricted feeding schedule. J Comp Physiol Psychol 47:362-363.

Harris RB, Zhou J, Redmann SM Jr, Smagin GN, Smith SR, Rodgers E, et al (1998): A leptin dose-response study in obese (ob/ob) and lean $(+/$ ?) mice.Endocrinology 139:8-19.

Hebebrand J, Blum WF, Barth N, Coners H, Englaro P, Juul A, et al (1997): Leptin levels in patients with anorexia nervosa are reduced in the acute stage and elevated upon short-term weight restoration. Mol Psychiatry 2:330-334.

Hebebrand J, Exner C, Hebebrand K, Holtkamp C, Casper RC, Remschmidt H, et al (2003): Hyperactivity in patients with anorexia nervosa and in semistarved rats: Evidence for a pivotal role of hypoleptinemia. Physiol Behav 79:25-37.

Hinney A, Bornscheuer A, Depenbusch M, Mierke B, Tolle A, Middeke K, et al (1998): No evidence for involvement of the leptin gene in anorexia nervosa, bulimia nervosa, underweight or early onset extreme obesity: Identification of two novel mutations in the coding sequence and a novel polymorphism in the leptin gene linked upstream region. Mol Psychiatry 3:539-543.

Holtkamp K, Hebebrand J, Mika C, Heer M, Heussen N, Herpertz-Dahlmann B (2004): High serum leptin levels subsequent to weight gain predict renewed weight loss in patients with anorexia nervosa. Psychoneuroendocrinology 29:791-797.

Holtkamp K, Herpertz-Dahlmann B, Mika C, Heer M, Heussen N, Fichter M, et al (2003): Elevated physical activity and low leptin levels co-occur in patients with anorexia nervosa. J Clin Endocrinol Metab 88:5169-5174.

Hulsey MG, Lu H, Wang T, Martin RJ, Baile CA (1998): Intracerebroventricular (i.c.v.) administration of mouse leptin in rats: Behavioral specificity and effects on meal patterns. Physiol Behav 65:445-455.

Kas MJ, van Dijk G, Scheurink AJ, Adan RA (2003): Agouti-related protein prevents self-starvation. Mol Psychiatry 8:235-240.

Kron L, Katz JL, Gorzynski G, Weiner H (1978): Hyperactivity in anorexia nervosa: A fundamental clinical feature. Compr Psychiatry 19:433-440.

Krugel U, Schraft T, Kittner H, Kiess W, Illes P (2003): Basal and feedingevoked dopamine release in the rat nucleus accumbens is depressed by leptin. Eur J Pharmacol 482:185-187.

Maffei M, Halaas J, Ravussin E, Pratley RE, Lee GH, Zhang Y, et al (1995): Leptin levels in human and rodent: Measurement of plasma leptin and ob RNA in obese and weight-reduced subjects. Nat Med 1:1155-1161. 
Mantzoros C, Flier JS, Lesem MD, Brewerton TD, Jimerson DC (1997): Cerebrospinal fluid leptin in anorexia nervosa: correlation with nutritional status and potential role in resistance to weight gain. J Clin Endocrinol Metab 82:1845-1851.

Pal R, Sahu A (2003): Leptin signaling in the hypothalamus during chronic central leptin infusion. Endocrinology 144:3789-3798.

Routtenberg A, Kuznes of AW (1967): Self-starvation of rats living in activity wheels on a restricted feeding schedule. J Comp Physiol Psychol 64:414421.

Satoh N, Ogawa Y, Katsuura G, Numata Y, Masuzaki H, Yoshimasa $Y$, et al (1998): Satiety effect and sympathetic activation of leptin are mediated by hypothalamic melanocortin system. Neurosci Lett 249:107-110.

Schwartz MW, Seeley RJ, Woods SC, Weigle DS, Campfield LA, Burn P, et al (1997): Leptin increases hypothalamic pro-opiomelanocortin mRNA expression in the rostral arcuate nucleus. Diabetes 46:2119-2123.

Schwartz MW, Woods SC, Porte D Jr, Seeley RJ, Baskin DG (2000): Central nervous system control of food intake. Nature 404:661-671.

Shalev U, Yap J, Shaham Y (2001): Leptin attenuates acute food deprivationinduced relapse to heroin seeking. J Neurosci 21:RC129.
Small CJ, Kim MS, Stanley SA, Mitchell JR, Murphy K, Morgan DG, et al (2001): Effects of chronic central nervous system administration of agouti-related protein in pair-fed animals. Diabetes 50:248-254.

Sullivan PF (1995): Mortality in anorexia nervosa. Am J Psychiatry 152:10731074

Surwit RS, Edwards CL, Murthy S, Petro AE (2000): Transient effects of longterm leptin supplementation in the prevention of diet-induced obesity in mice. Diabetes 49:1203-1208.

Thiele TE, van Dijk G, Campfield LA, Smith FJ, Burn P, Woods SC, et al (1997): Central infusion of GLP-1, but not leptin, produces conditioned taste aversions in rats. Am J Physiol 272:R726-R730.

van Dijk G (2001): The role of leptin in the regulation of energy balance and adiposity. J Neuroendocrinol 13:913-921.

Velkoska E, Morris MJ, Burns P, Weisinger RS (2003): Leptin reduces food intake but does not alter weight regain following food deprivation in the rat. Int J Obes Relat Metab Disord 27:48-54.

Zhang Y, Proenca R, Maffei M, Barone M, Leopold L, Friedman JM (1994): Positional cloning of the mouse obese gene and its human homologue. Nature 372:425-432. 